\title{
Efeito da suplementação de creatina, associada ou não ao treinamento de força, sobre a peroxidação lipídica em mulheres idosas
}

CDD. 20.ed. 796.018

796.022

796.027

\author{
Christiano Robles Rodrigues ALVES* \\ Carlos Alberto Abujabra MEREGE FILHO** \\ Paulo Roberto JANNING* \\ Luiz Roberto Grassmann BECHARA* \\ Rafael de Almeida AZEVEDO* \\ Fabiana Braga BENATTI ${ }^{* * * *}$ \\ Rosa Maria Rodrigues PEREIRA** \\ Ana Lúcia de Sá PINTO** \\ Patrícia Chakur BRUM* \\ Bruno GUALANO****
}

*Escola de Educação Física e Esporte, Universidade de São Paulo.

${ }^{* *}$ Faculdade de Medicina, Universidade de São Paulo.

\section{Resumo}

0 objetivo desse trabalho foi avaliar o efeito da suplementação de creatina associada ou não ao treinamento de força sobre a peroxidação lipídica em mulheres idosas. Foi conduzido um estudo clínico, randomizado, duplo-cego e controlado por placebo, no qual mulheres idosas foram randomizadas para compor quatro grupos: 1 ) suplementação com placebo $(P L ; n=10) ; 2)$ suplementação com creatina $(C R ; n=10)$; 3) suplementação com placebo associado ao treinamento de força $(P L+T R ; n=6)$; e 4) suplementação com creatina associado ao treinamento de força ( $R+T R ; n=8)$. Antes (PRE) e após 24 semanas (POS) de intervenção, foram coletadas amostras de sangue para posterior análise das concentrações plasmáticas de hidroperóxidos lipídicos por espectrofotometria. Nenhuma diferença estatística foi observada na concentração de hidroperóxidos lipídicos entre os grupos $(\mathrm{PL}$ : $\mathrm{PRE}=48,7 \pm 36,9 ; \mathrm{POS}=29,3 \pm 18,8$; delta $=-13,0$ $\pm 26,8 ;$ CR: PRE $=51,0 \pm 46,0 ;$ POS $=54,2 \pm 51,6 ;$ delta $=-8,6 \pm 30,2 ;$ PL+TR: PRE $=33,0 \pm 11,2 ;$ POS $=$ $47,3 \pm 31,6 ; \Delta=14,3 \pm 39,2 ;$ CR+TR: PRE $=18,5 \pm 10,1 ;$ POS $=28,1 \pm 17,9 ;$ delta $=9,7 \pm 16,4$ pmol.mg $^{-1}$ de proteína total; $p=0,17)$. A suplementação de creatina associada ou não ao treinamento de força não afetou a peroxidação lipídica, um importante marcador de estresse oxidativo no plasma, em mulheres idosas.

Palavras-Chave: Estresse oxidativo; Radicas livres; Nutrição; Exercício físico; Envelhecimento.

\section{Introdução}

As espécies reativas de oxigênio (EROs) são capazes de oxidar componentes celulares essenciais como as proteínas, os nucleotídeos, os lipídios e, principalmente, os ácidos graxos poli-insaturados. Consequentemente, essa reação com os ácidos graxos poli-insaturados presentes nas membranas e nas lipoproteínas inicia um processo em cadeia denominado peroxidação lipídica ${ }^{1}$. O aumento desse processo pode ser resultado do estresse oxidativo exacerbado, estando associado ao surgimento de diversas doenças crônicas, como as neurodegenerativas, as cardiovasculares e o câncer ${ }^{2-7}$. Além disso, há décadas que o próprio processo de envelhecimento vem sendo diretamente relacionado a esse quadro ${ }^{8-10}$.

As EROs são encontradas em todos sistemas biológicos, sendo que o peróxido de hidrogênio $\left(\mathrm{H}_{2} \mathrm{O}_{2}\right)$ merece destaque por ser um metabólito relativamente estável e capaz de atravessar camadas lipídicas, reagindo com diversos alvos, como a membrana eritrocitária ou proteínas ligadas ao ferro ${ }^{4,11}$. Como defesa a essa reação, as células apresentaram mecanismos antioxidantes capazes de prevenir ou limitar os danos intracelulares. Dentre eles, destacam-se as enzimas que inativam os peróxidos e as proteínas capazes de remover os metais 
de transição (ex: ferro $)^{1}$. Dessa forma, estratégias não farmacológicas capazes de aumentar a defesa antioxidante do organismo passam a ser de grande interesse científico e aplicação clínica.

Recentes evidências indicam que a suplementação de creatina (ácido $\alpha$-metil guanidino acético) apresenta efeitos terapêuticos em doenças nas quais o estresse oxidativo exacerbado exerce um papel importante (ex: doença de Huntington e doença de Parkinson) $)^{12-13}$. De fato, esses efeitos antioxidantes parecem ser resultados de adaptações diretas e/ou indiretas à suplementação desse nutriente. Experimentos conduzidos "in vitro", por exemplo, demonstraram que a adição de creatina em diferentes culturas de células ocasionou efeitos citoprotetores ante a insultos oxidantes como o $\mathrm{H}_{2} \mathrm{O}_{2}{ }^{14}$. Em adição, realça-se a hipótese de que a creatina possa atenuar a formação das EROs "indiretamente", através de seu acoplamento à adenosina trifosfato (ATP) dentro da mitocôndria. Esse acoplamento resultaria, em última análise, em uma melhor respiração mitocondrial e redução da energia livre necessária para a síntese de ATP, diminuindo a liberação de elétrons para a formação das $\mathrm{EROs}^{15}$.

Outra estratégia não farmacológica potencialmente capaz de inibir a formação de EROs é o treinamento físico. É bem estabelecido que o treinamento físico aeróbio produz importantes adaptaçóes

\section{Método}

\section{Amostra e desenho experimental}

O estudo foi aprovado pela Comissão de Ética para Análise de Projetos de Pesquisa (CAPPesq) da Diretoria Clínica do Hospital das Clínicas da Faculdade de Medicina da Universidade de São Paulo (Protocolo de Pesquisa no 0472/10). Os resultados apresentados aqui fazem parte de um estudo clínico maior cadastrado no clinicaltrials.gov (NCT01164020) e desenvolvido entre fevereiro de 2011 e dezembro de 2012, em São Paulo, Brasil. Todos os sujeitos foram informados sobre os riscos envolvidos antes de assinarem o termo de consentimento livre e esclarecido.

Foi conduzido um estudo clínico, randomizado, duplo-cego e controlado por placebo, cujo objetivo central foi avaliar a função cognitiva em mulheres idosas ${ }^{27}$. Com o intuito de testar a hipótese de que as intervençóes propostas poderiam modular as concentraçôes plasmáticas de hidroperóxidos lipídicos, foi selecionada uma subamostra de 36 morfofuncionais e biomoleculares no organismo, podendo atenuar ou até mesmo reverter diferentes quadros patológicos ${ }^{16-18}$. Dentre essas adaptaçóes, ressalta-se uma diminuição da produção de EROs e/ou um aumento da defesa antioxidante total ${ }^{19-24}$. Interessantemente, o treinamento de força parece ocasionar adaptaçóes antioxidantes similares ao treinamento físico aeróbio ${ }^{25}$. CAKIR-ATABEK et al..$^{25}$ demonstraram que após seis semanas de dois diferentes programas de treinamento de força (moderada ou alta intensidade) houve uma redução das concentrações sanguíneas de malondialdeído associado a um aumento nas concentrações sanguíneas de glutationa em jovens. Esses resultados sugerem o aumento da defesa antioxidante do organismo em resposta ao treinamento de força.

A combinação da suplementação de creatina com o treinamento de força parece ser uma estratégia efetiva em combater a perda de massa muscular e o declínio de qualidade de vida na população idosa ${ }^{26}$. Entretanto, a influência dessa combinaçáo sobre outros parâmetros fisiológicos e funcionais ainda foi pouco explorada. Portanto, o objetivo desse estudo foi avaliar a ação da suplementação de creatina associada ou não ao treinamento de força sobre a peroxidação lipídica, um importante marcador de estresse oxidativo, em mulheres idosas.

voluntárias. Antes da intervenção, todas as voluntárias passaram por avaliação médica e teste ergométrico. Os critérios de exclusão foram: presença de doenças crônicas (ex: cardiovasculares, osteomiarticulares, metabólicas, psiquiátricas, endócrinas) e tabagismo. Todas as voluntárias não eram usuárias de creatina e não participavam de nenhum programa de atividade física regular há, pelo menos, um ano.

As voluntárias foram aleatoriamente alocadas para compor um dos quatro grupos experimentais, a saber: 1) suplementação com placebo $(\mathrm{PL} ; \mathrm{n}=$ $10)$; 2) suplementação com creatina ( $\mathrm{CR} ; \mathrm{n}=10)$; 3) suplementação com placebo associado ao treinamento de força (PL+TR; $\mathrm{n}=8)$; e 4) suplementação com creatina associado ao treinamento de força $(\mathrm{CR}+\mathrm{TR} ; \mathrm{n}=8)$. Antes (PRE) e após 24 semanas (POS) de intervenção, 72 horas após a última sessão de treinamento (para os grupos PL+TR e CR+TR), foram coletadas amostras de sangue da veia antecubital em tubo contendo EDTA. As amostras foram 
centrifugadas e o plasma foi armazenado para posterior análise das concentraçóes de hidroperóxidos lipídicos. As voluntárias estavam de jejum noturno $(\sim 12 \mathrm{~h})$ e ficaram em situação de repouso durante pelo menos 30 minutos antes da coleta de sangue. A FIGURA 1 ilustra o desenho experimental.

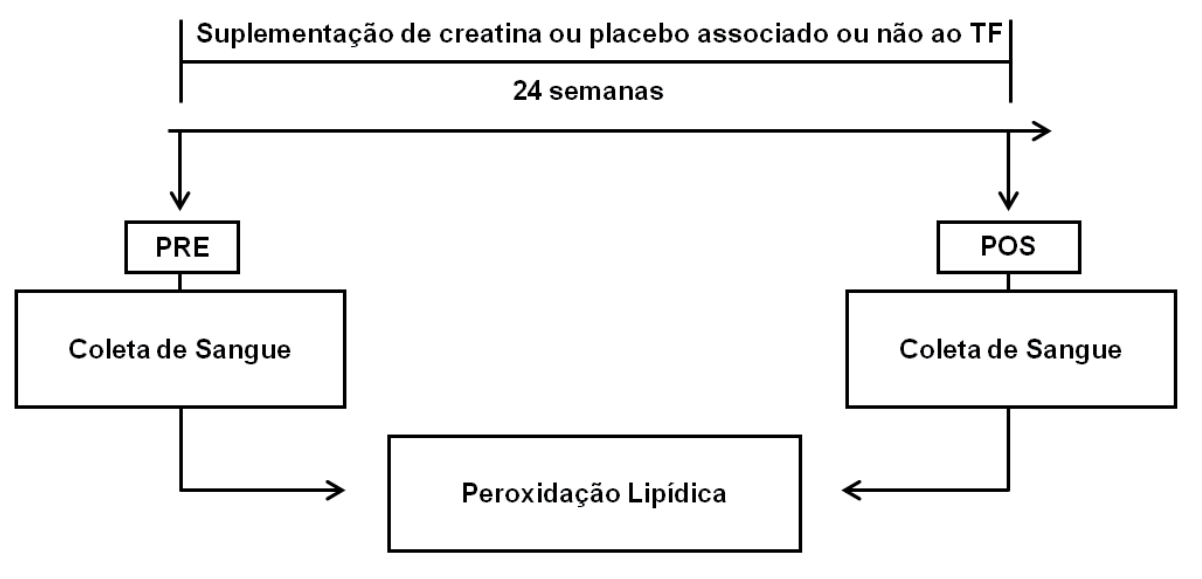

FIGURA 1 - Desenho experimental.

\section{Suplementação de creatina}

Os grupos $\mathrm{CR}$ e $\mathrm{CR}+\mathrm{TR}$ receberam quatro doses diárias de $5 \mathrm{~g}$ de creatina monohidratada durante cinco dias. Após esse período, foram ministradas uma dose diária de $5 \mathrm{~g}$ de creatina até o final do estudo. Os grupos PL e PL + TR receberam as mesmas doses de dextrose (placebo). Para manter o vendamento do estudo, uma nutricionista ficou responsável por codificar os suplementos, sendo que nem os pesquisadores nem as voluntárias sabiam qual suplemento estava sendo ingerido. Os grupos foram revelados apenas ao final das análises estatísticas.

\section{Treinamento de força}

O treinamento de força foi ministrado duas vezes por semana. Cada sessão consistiu de três séries de 12 a 15 repetições máximas (RM) para sete exercícios de força, a saber: supino, "leg press", puxador costas, remada, cadeira extensora, agachamento e abdominais. Foi permitido um descanso de um minuto entre cada série. $\mathrm{Na}$ primeira semana de treinamento, as cargas utilizadas foram submáximas no intuito de propiciar melhor aprendizagem da execução dos exercícios. A partir da segunda semana, a progressão das cargas foi realizada sempre que a voluntária conseguia realizar mais de $15 \mathrm{RM}$ em duas sessóes de treino consecutivas.

\section{Peroxidação lipídica}

Os hidroperóxidos lipídicos são produtos primários da peroxidação dos ácidos graxos poliinsaturados. A avaliação da concentração de hidroperóxidos em amostras biológicas utiliza o alaranjado de xilenol. Este método baseia-se no princípio de que os hidroperóxidos oxidam ferro II a ferro III, o qual reage com o alaranjado de xilenol, produzindo um cromóforo que tem absorção máxima em 560 nm ${ }^{28}$.

A quantificação de hidroperóxidos lipídicos totais foi realizada no plasma das voluntárias por espectrofotometria. Em uma alíquota de $100 \mathrm{uL}$ do plasma, as proteínas foram precipitadas com ácido tricloroacético $(10 \%)$ e centrifugadas $(12.000 \mathrm{~g}$ durante 15 min a $4^{\circ} \mathrm{C}$ ). Em seguida, o sobrenadante de cada amostra foi pipetado em uma placa de 96 wells em triplicata (20 uL em cada poço). Foi adicionado 180 $\mathrm{uL}$ do reagente FOX ( $1 \mathrm{mM}$ sulfato de ferro; 250 $\mathrm{mM} \mathrm{H}_{2} \mathrm{SO}_{4} ; 1 \mathrm{mM}$ alaranjado de xilenol; e $\mathrm{H}_{2} \mathrm{O}$ destilada) em cada poço e incubado protegido de luz em temperatura ambiente por $30 \mathrm{~min}$. A absorbância da amostra foi lida em espectrofotômetro no comprimento de onda de $560 \mathrm{~nm}$. Os resultados foram normalizados para as concentraçôes de proteínas realizadas pelo método Bradford na mesma amostra de plasma ${ }^{29}$. Portanto, os resultados de hidroperóxidos lipídicos estão expressos em pmol. $\mathrm{mg}^{-1}$ de proteína total. 


\section{Análise estatística}

Foram calculados escores delta ( $\Delta$; POS - PRE) para os valores de hidroperóxidos lipídicos e, em seguida, foi aplicada ANOVA para um fator para a comparação entre os grupos. Além disso, para testar

\section{Resultados}

Duas pacientes do grupo $\mathrm{PL}+\mathrm{TR}$ se retiraram do estudo por motivos pessoais e recusaram a realizar os testes no período POS. Portanto, 34 voluntárias foram analisadas nesse estudo $(\mathrm{PL}=10, \mathrm{CR}=10$, $\mathrm{PL}+\mathrm{TR}=6, \mathrm{CR}+\mathrm{TR}=8)$. Dentre essa amostra, seis $(60 \%)$, sete $(70 \%)$, três $(50 \%)$ e cinco $(62,5 \%)$ voluntárias, dos grupos PL, CR, PL+TR e CR+TR, respectivamente, foram capazes de identificar o suplemento que estavam ingerindo, sendo que nenhuma diferença estatística foi observada entre os grupos ( $\mathrm{p}$ $=0,70)$. Todas as voluntárias autorreportam seguir adequadamente o protocolo de suplementação. o vendamento do estudo, foi aplicado o teste de QuiQuadrado $\left(\chi^{2}\right)$ para avaliar a proporção de voluntárias entre os grupos que acertaram o suplemento ingerido.

Foi adotado o valor de $\mathrm{p}<0,05$ para se rejeitar a hipótese nula. Os resultados são expressos como média \pm desvio padrão.

Nenhuma diferença estatística foi observada para o consumo alimentar entre os grupos ( $\mathrm{p}>0,05$ para todas as variáveis; TABELA 1).

Como demonstrado na FIGURA 2, nenhuma diferença estatística foi observada na concentração de hidroperóxidos lipídicos entre os quatro grupos experimentais (PL: $\mathrm{PRE}=48,7 \pm 36,9$; $\mathrm{POS}=29,3$ $\pm 18,8 ; \Delta=-13,0 \pm 26,8 ; \mathrm{CR}: \mathrm{PRE}=51,0 \pm 46,0$; POS $=54,2 \pm 51,6 ; \Delta=-8,6 \pm 30,2 ;$ PL+TR: PRE $=33,0 \pm 11,2 ; \mathrm{POS}=47,3 \pm 31,6 ; \Delta=14,3 \pm 39,2$; CR+TR: PRE $=18,5 \pm 10,1 ; \mathrm{POS}=28,1 \pm 17,9 ; \Delta$ $=9,7 \pm 16,4$ pmol. $\mathrm{mg}^{-1}$ de proteína total; $\mathrm{p}=0,17$ ). 
TABELA 1 - Consumo alimentar antes (PRÉ) e após (PÓS) as intervenções.

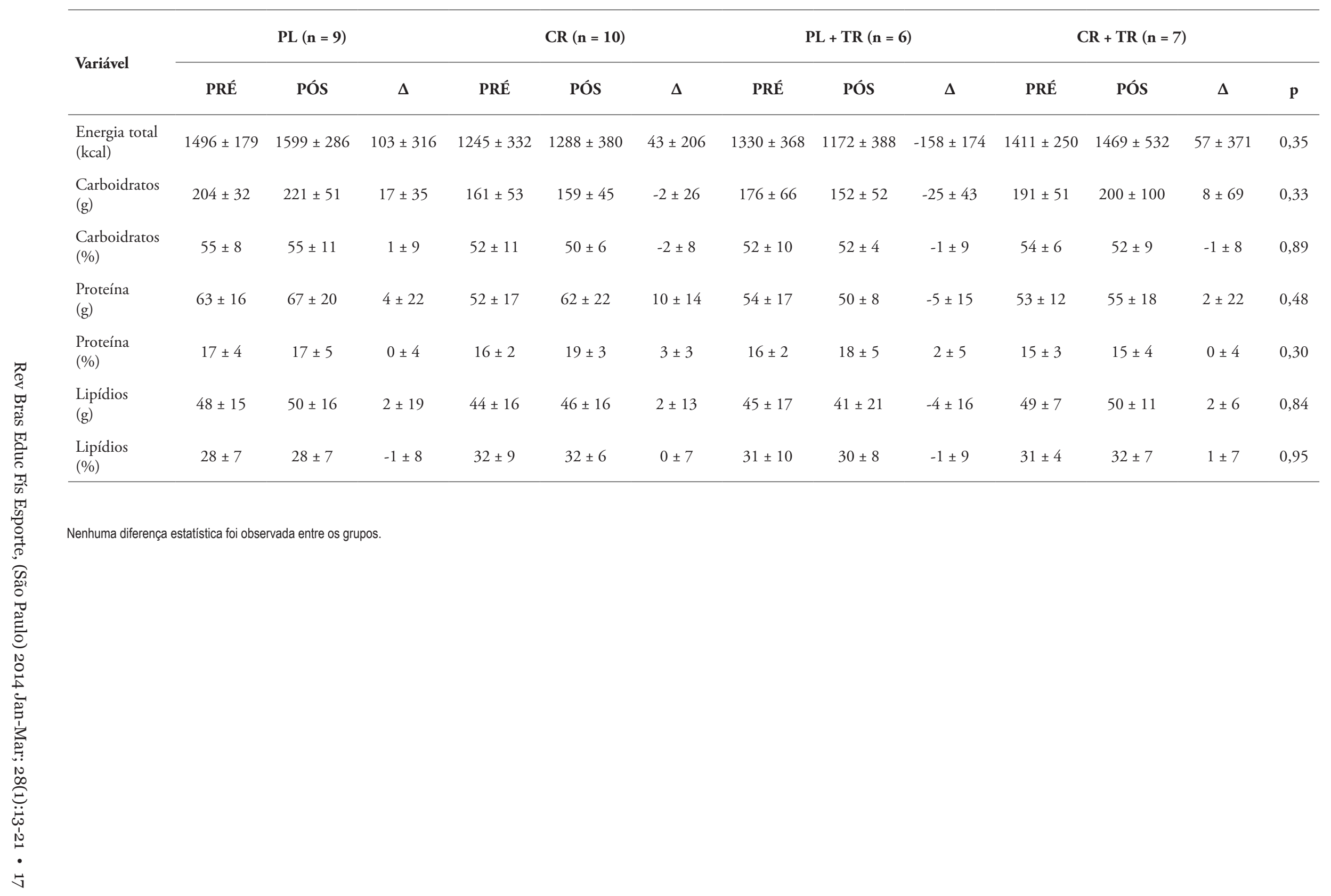


Nenhuma diferença estatística foi observada entre os quatro grupos experimentais $(p=0,17)$.

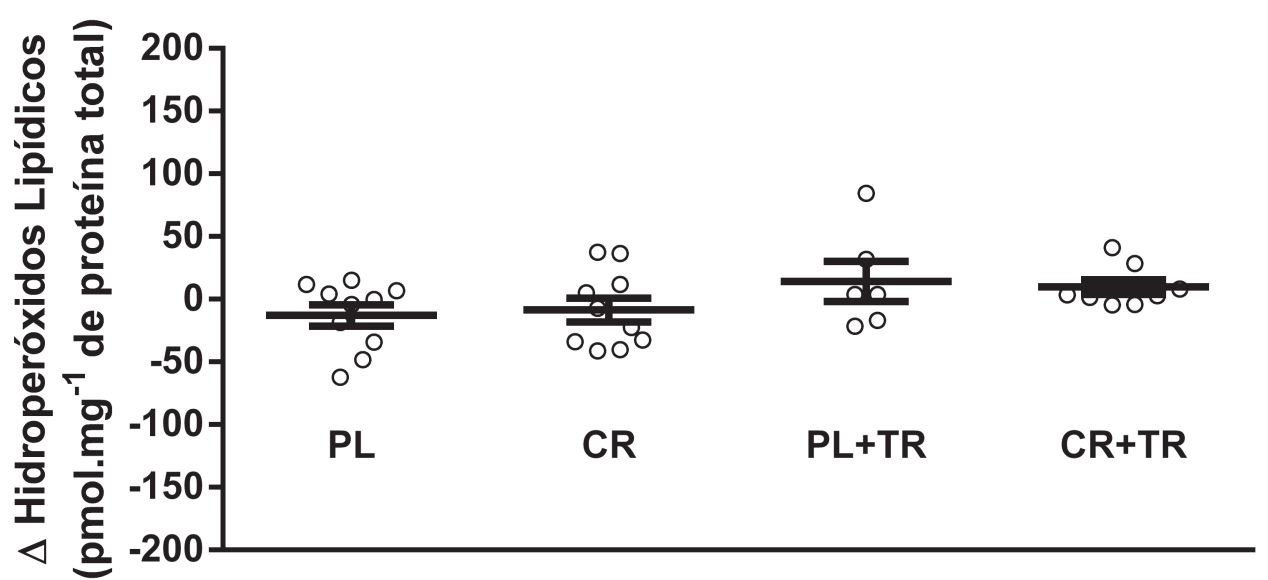

FIGURA 2 - Delta absoluto $(\Delta)$ para as concentrações plasmáticas de hidroperóxidos lipídicos antes e após 24 semanas de intervenção.

\section{Discussão}

O objetivo do presente estudo foi avaliar a concentração plasmática de hidroperóxidos lipídicos, um importante marcador de estresse oxidativo, em mulheres idosas submetidas a um protocolo crônico de suplementação de creatina aliado ou não ao treinamento de força. Nossos achados não corroboram a hipótese de que essas intervençóes possam ser capazes de modular o balanço redox durante o processo de envelhecimento, uma vez que não foram encontradas diferenças na peroxidação lipídica plasmática entre os grupos experimentais.

Sabe-se que a creatina tem como papel central a provisão rápida de energia (via grupo $\mathrm{N}$ - fosforil), através de reação catalizada pela enzima creatina quinase. Além disso, a creatina é responsável pela transferência de energia da mitocôndria para o citosol, especialmente em tecidos de alta demanda energética, como o músculo esquelético e o cérebro ${ }^{30}$. Evidências sugerem que um possível mecanismo pelo qual a suplementação de creatina promove benefícios clínicos em miopatias e doenças neurodegenerativas envolve a atenuação do estresse oxidativo, via ação antioxidante direta e indireta ${ }^{14-15,31}$. Contudo, no presente estudo, o grupo suplementado com creatina não apresentou nenhuma redução nas concentraçôes de hidroperóxidos lipídicos plasmáticos quando comparado ao grupo suplementado com placebo. Ao encontro desses achados, nosso grupo bem como outros não encontram efeitos benéficos desse suplemento em indicadores de estresse oxidativo em modelos animais. Após nove semanas de suplementação, não foram observadas diferenças na peroxidação lipídica no músculo esquelético, no coração, no vaso e no plasma em ratos espontaneamente hipertensos ${ }^{32}$. Silva et al. ${ }^{33}$ suplementaram ratos com creatina por duas semanas e submeteram os animais a uma sessão de exercício em esteira declinada até a exaustão. Os autores também não observaram diferenças na produção de superóxido, nos níveis de espécies reativas ao ácido tiobarbitúrico (TBARS), e na atividade das enzimas superóxido dismutase, catalase e glutationa peroxidase no músculo quadríceps dos animais suplementados com creatina quando comparados aos animais suplementados com solução salina, indicando que a ingestão de creatina não modula o estresse oxidativo após um exercício de ação excêntrica ${ }^{19}$. Estudos em humanos também corroboram os presentes achados. KINGSLEY et al. ${ }^{34}$, por exemplo, suplementaram com creatina jovens fisicamente ativos durante uma semana e avaliaram diversos marcadores plasmáticos de estresse oxidativo (incluindo a peroxidação lipídica) antes, logo após e 24 h após uma sessão de exercício físico em cicloergômetro até a exaustão. A suplementação não alterou a concentração de hidroperóxidos lipídicos, a resistência do LDL ao estresse oxidativo e as concentraçôes de diversas substâncias antioxidantes não enzimáticas como, por exemplo, o $\beta$-caroteno e a vitamina $C^{3}$.

Portanto, a despeito dos promissores achados em cultura de células, a suplementação de creatina per se parece náo influenciar no balanço redox em ratos ou humanos, hipótese reforçada pelo presente estudo ${ }^{14,31}$.

Em contrapartida, RAHimi et al. ${ }^{35}$ observaram uma atenuação da excreção urinária de 8 -OHdG e 
da concentração plasmática de malondialdeído em indivíduos praticantes de treinamento de força após sete dias de suplementação de creatina, sugerindo que a associação da suplementação de creatina ao treinamento de força possa apresentar efeitos sinérgicos sobre o estresse oxidativo. Em nosso estudo, entretanto, também não encontramos nenhuma diferença na peroxidação lipídica após a suplementação de creatina associada ao treinamento de força. Em divergência aos nossos achados, Percário et al. ${ }^{36}$ avaliaram jovens que praticavam treinamento de força regularmente (atletas de handebol) e, ao contrário do esperado, observaram uma diminuição da capacidade antioxidante total após a suplementação de creatina. Portanto, os resultados contraditórios na literatura reforçam a necessidade de se explorar mais profundamente o papel desse nutriente sobre o estresse oxidativo em humanos.

Por fim, é importante salientar que o treinamento de força isolado também não exerceu efeitos positivos no presente estudo. Em contrapartida, CAKIRAtABeK et al. ${ }^{25}$ observaram que, após seis semanas de treinamento de força, houve uma redução das concentraçôes sanguíneas de malondialdeído associado a um aumento nas concentraçóes sanguíneas de glutationa, sugerindo um aumento da defesa antioxidante do organismo em resposta a esse tipo de treinamento. Possivelmente, as diferenças nos protocolos de treinamento, nos marcadores de estresse oxidativo utilizados e, principalmente, nas populaçóes estudadas, podem explicar os resultados divergente. A esse propósito, cabe destacar que, enquanto CAKIR-ATABEK et al..$^{25}$ estudaram homens jovens, nosso estudo foi composto por mulheres idosas, sendo plausível especular que o treinamento de força tenha seus efeitos benéficos limitados em condições específicas, como no envelhecimento. Novos estudos que busquem avaliar diferentes intensidades de treinamento de força sobre marcadores de estresse oxidativo em idosos também se fazem necessários.

O presente estudo apresenta limitaçóes que devem ser consideradas. Primeiramente, embora tenha sido avaliado o consumo alimentar de macronutrientes, não avaliamos a ingestão de outras substâncias antioxidantes (ex: vitaminas) na dieta, sendo este um possível fator de interferência nos resultados. Em segundo lugar, é bem estabelecido que o processo de envelhecimento acompanha modificaçóes no controle do balanço redox sistêmico, porém esse estudo náo incluiu um grupo controle jovem para comprovar o quadro de estresse oxidativo exacerbado em nossa amostra, razão pela qual não é possível descartar a hipótese de que a ineficácia das intervençóes testadas nesse estudo se devam, parcialmente, ao fato de que nossas voluntárias possam ter apresentado valores "normais" de estresse oxidativo ("efeito teto").

Em conclusão, a suplementação de creatina associada ou náo ao treinamento de força náo afetou a peroxidaçáo lipídica plasmática em mulheres idosas, sugerindo que essas estratégias não modificam o estresse oxidativo nessa população.

\begin{abstract}
Effects of creatine supplementation associated or not with strength training upon lipid peroxidation in elderly women

The aim of this study was to evaluate the effects of creatine supplementation associated or not with strength training upon lipid peroxidation in older women. This was a clinical, randomized, double-blind, placebocontrolled trial. Older women were randomly allocated into four groups: 1) placebo supplementation (PL, $n=10), 2)$ creatine supplementation (CR; $n=10), 3$ ) placebo supplementation associated with strength training (PL $+R T, n=6)$ and 4) creatine supplementation associated with strength training ( $C R+R T, n=$ 8). Before (PRE) and after 24 weeks (POST), blood samples were collected to measure lipid hydroperoxides concentration by spectrophotometry. No statistical difference was observed on the lipid hydroperoxides concentration between groups (PL: PRE $=48.7 \pm 36.9 ; \mathrm{POST}=29.3 \pm 18.8 ; \Delta=-13.0 \pm 26.8 ; \mathrm{CR}: \mathrm{PRE}=$ $51.0 \pm 46.0 ; \mathrm{POST}=54.2 \pm 51.6 ; \Delta=-8.6 \pm 30.2 ;+\mathrm{PLTR}: \mathrm{PRE}=33.0 \pm 11.2 ; \mathrm{POST}=47.3 \pm 31.6, \Delta=14.3$ $\pm 39.2 ; \mathrm{CR}+\mathrm{TR}: \mathrm{PRE}=18.5 \pm 10.1 ; \mathrm{POST}=28.1 \pm 17.9, \Delta=9.7 \pm 16.4$ pmol. $\mathrm{mg}^{-1}$ of total protein, $\mathrm{p}=0.17$ ). Creatine supplementation associated or not with strength training did not affect the lipid peroxidation, an important plasmatic marker of oxidative stress, in elderly women.
\end{abstract}

KEY WORDS: Oxidative stress; Free radicals; Nutrition; Physical exercise; Aging. 


\section{Referências}

1. De Zwart LL, Meerman JH, Commandeur JN, Vermeulen NP. Biomarkers of free radical damage applications in experimental animals and in humans. Free Radic Biol Med. 1999;26:202-26.

2. Di Carlo M, Giacomazza D, Picone P, Nuzzo D, San Biagio PL. Are oxidative stress and mitochondrial dysfunction the key players in the neurodegenerative diseases? Free Radic Res. 2012;46:1327-38.

3. Butterfield DA, Lauderback CM. Lipid peroxidation and protein oxidation in Alzheimer's disease brain: potential causes and consequences involving amyloid betapeptide-associated free radical oxidative stress. Free Radic Biol Med. 2002;32:1050-60.

4. Shao D, Oka S, Brady CD, Haendeler J, Eaton P, Sadoshima J. Redox modification of cell signaling in the cardiovascular system. J Mol Cell Cardiol. 2012;52:550-58.

5. Kim GH, Ryan JJ, Archer SL. The role of redox signaling in epigenetics and cardiovascular disease. Antioxid Redox Signal. 2013;18:1920-36.

6. Luo J, Solimini NL, Elledge SJ. Principles of cancer therapy: oncogene and non-oncogene addiction. Cell. 2009;136:823-37.

7. Khandrika L, Kumar B, Koul S, Maroni P, Koul HK. Oxidative stress in prostate cancer. Cancer Lett. 2009;282:125-36.

8. Knight JA. The biochemistry of aging. Adv Clin Chem. 2000;35:1-62.

9. Harman D. Free radical theory of aging. Mutat Res. 1992;275:257-66.

10. Harman D. Aging: a theory based on free radical and radiation chemistry. J Gerontol. 1956;11:298-300.

11. Ferreira ALA, Matsubara LS. Radicais livres: conceitos, doenças relacionadas, sistema de defesa e estresse oxidativo. Rev Assoc Med Brasil. 1997;43:61-8.

12. Matthews RT, Ferrante RJ, Klivenyi P, et al. Creatine and cyclocreatine attenuate MPTP neurotoxicity. Exp Neurol. 1999;157:142-9.

13. Matthews RT, Yang L, Jenkins BG, et al. Neuroprotective effects of creatine and cyclocreatine in animal models of Huntington's disease. J Neurosci. 1998;18:156-63.

14. Sestili P, Martinelli C, Bravi G, et al. Creatine supplementation affords cytoprotection in oxidatively injured cultured mammalian cells via direct antioxidant activity. Free Radic Biol Med. 2006;40:837-49.

15. Sestili P, Martinelli C, Colombo E, et al. Creatine as an antioxidant. Amino Acids. 2011;40:1385-96.

16. Egan B, Zierath JR. Exercise metabolism and the molecular regulation of skeletal muscle adaptation. Cell Metabolism. 2013;17:162-84.

17. Brum PC, Bacurau AV, Medeiros A, Ferreira JC, Vanzelli AS, Negrão CE. Aerobic exercise training in heart failure: impact on sympathetic hyperactivity and cardiac and skeletal muscle function. Braz J Med Biol Res. 2011;44:827-35.

18. Gualano B, Pinto AL, Perondi MB, et al. Therapeutic effects of exercise training in patients with pediatric rheumatic diseases. Rev Bras Reumatol. 2011;51:490-6.

19. Silva LA, Bom KF, Tromm CB, et al. Effect of eccentric training on mitochondrial function and oxidative stress in the skeletal muscle of rats. Braz J Med Biol Res. 2013;46:14-20.

20. Ferreira JC, Bacurau AV, Bueno Junior CR, et al. Aerobic exercise training improves $\mathrm{Ca} 2+$ handling and redox status of skeletal muscle in mice. Exp Biol Med (Maywood). 2010;235:497-505.

21. Silva LA, Pinho CA, Scarabelot KS, et al. Physical exercise increases mitochondrial function and reduces oxidative damage in skeletal muscle. Eur J Appl Physiol. 2009;105:861-7.

22. Finaud J, Lac G, Filaire E. Oxidative stress: relationship with exercise and training. Sports Med. 2006;36:327-58.

23. Venditti P, Masullo P, DiMeo S. Effect of training on $\mathrm{H}_{2} \mathrm{O}_{2}$ release by mitochondria from rat skeletal muscle. Arch Biochem Biophys. 1999;372:315-20.

24. Powers SK, Criswell D, Lawler J, et al. Rigorous exercise training increases superoxide dismutase activity in ventricular myocardium. Am J Physiol. 1993;265:2094-8.

25. Cakir-Atabek H, Demir S, PinarbaŞili RD, Gündüz N. Effects of different resistance training intensity on indices of oxidative stress. J Strength Cond Res. 2010;24:2491-7.

26. Rawson ES, Venezia AC. Use of creatine in the elderly and evidence for effects on cognitive function in young and old. Amino Acids. 2011;40:1349-62.

27. Alves CR, Merege Filho CA, Benatti FB, et al. Creatine supplementation associated or not with strength training upon emotional and cognitive measures in older women: a randomized double-blind study. PLoS One. 2013;8: e76301.

28. Nourooz-Zadeh J, Tajaddini-Sarmadi J, Wolff SP. Measurement of plasma hydroperoxide concentrations by the ferrous oxidation-xylenol orange assay in conjunction with triphenylphosphine. Anal Biochem. 1994;220:403-9. 
29. Bradford MM. A rapid and sensitive method for the quantitation of microgram quantities of protein utilizing the principle of protein-dye binding. Anal Biochem. 1976;72:248-54.

30. Wyss M, Kaddurah-Daouk R. Creatine and creatinine metabolism. Physiol Ver. 2000;80:1107-213.

31. Lawler JM, Barnes WS, Wu G, Song W, Demaree S. Direct antioxidant properties of creatine. Biochem Biophys Res Commun. 2002;290:47-52.

32. Alves CR, Murai IH, Ramona P, et al. No effect of creatine supplementation on oxidative stress and cardiovascular parameters in spontaneously hypertensive rats. Int Soc Sports Nutr. 2012;9:13.

33. Silva LA, Tromm CB, Da Rosa G, et al. Creatine supplementation does not decrease oxidative stress and inflammation in skeletal muscle after eccentric exercise. J Sports Sci. 2013;31:1164-76.

34. Kingsley M, Cunningham D, Mason L, Kilduff LP, McEneny J. Role of creatine supplementation on exercise-induced cardiovascular function and oxidative stress. Oxid Med Cell Longev. 2009;2:247-54.

35. Rahimi R. Creatine supplementation decreases oxidative DNA damage and lipid peroxidation induced by a single bout of resistance exercise. J Strength Cond Res. 2011;25:3448-55.

36. Percário S, Domingues SP, Teixeira LF, et al. Effects of creatine supplementation on oxidative stress profile of athletes. J Int Soc Sports Nutr. 2012;9:56.

ENDEREÇO

Bruno Gualano

Escola de Educação Física e Esporte - USP

Recebido para publicação: 04/06/2013

Av. Prof. Mello Moraes, 65

05508-030 - São Paulo - SP - BRASIL

Aceito: 21/10/2013

e-mail: gualano@usp.br

Rev Bras Educ Fís Esporte, (São Paulo) 2014 Jan-Mar; 28(1):13-21 • 21 